\title{
Article
}

\section{The hoof renewal time of Thoroughbred foals from birth}

Curtis, Simon, Martin, Jaime and Hobbs, Sarah Jane

Available at http://clok.uclan.ac.uk/12534/

Curtis, Simon, Martin, Jaime and Hobbs, Sarah Jane ORCID: 0000-0002-15528647 (2014) The hoof renewal time of Thoroughbred foals from birth. Veterinary Journal, 201 (1). pp. 116-117. ISSN 1090-0233

It is advisable to refer to the publisher's version if you intend to cite from the work. http://dx.doi.org/10.1016/j.tvjl.2014.04.012

For more information about UCLan's research in this area go to http://www.uclan.ac.uk/researchgroups/ and search for <name of research Group>.

For information about Research generally at UCLan please go to http://www.uclan.ac.uk/research/

All outputs in CLoK are protected by Intellectual Property Rights law, including Copyright law. Copyright, IPR and Moral Rights for the works on this site are retained by the individual authors and/or other copyright owners. Terms and conditions for use of this material are defined in the policies page.

\section{CLoK}

Central Lancashire online Knowledge www.clok.uclan.ac.uk

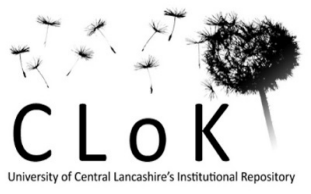


Title: The hoof renewal time of Thoroughbred foals from birth ( $\left.8^{\text {th }} \mathrm{draft}\right)$

Authors: Curtis SJ*, Martin $\mathrm{JH}^{\star *}$, Hobbs SJ*

Affiliations: *University of Central Lancashire, Preston, UK; ${ }^{* *}$ Myerscough College, Preston, UK

\begin{abstract}
:
Introduction: Thoroughbred foals are born with fully developed hooves and stand within minutes of birth. A ring in the hoof horn occurs at birth and grows down the hoof wall, separating the fetal hoof (distal) and foal hoof (proximal). Birth rings in hoof horn have been noted in other species and used to estimate age. Hoof wall renewal in all ages of horse has been poorly reported. Furthermore horn growth and complete hoof capsule renewal has not been measured in Thoroughbred foals. Partial hoof wall avulsions are relatively common. The objective was to measure the time taken for the fetal hoof of newborn foals to grow to the bearing border and be replaced by hoof grown since birth.
\end{abstract}

Method: Thoroughbred foals $(\mathrm{N}=150)$ on four Newmarket stud farms were studied during June to September. The age of the foal and the day that routine hoof trimming removed the remnants of the fetal hoof of the front hooves was recorded. Foals that were on restricted exercise, ill or where the remnants of the fetal hoof still remained after trimming were excluded from the data. 45 foals fulfilled the criteria. The data were tabulated in Excel, analysed in Minitab and assessed for normality (AndersonDarling).

Results: The mean age at which the fetal hoof was removed with routine trimming was $145 \pm 15$ days (95\% confidence interval, 141.77-147.16), range 120-165 days.

Conclusions: Thoroughbred foals replaced the fetal hoof half the time given for mature horses (270-365 days). Knowing the time of hoof renewal will allow accurate predictions of healing to be made in cases of partial hoof wall avulsion and other hoof lesions and may assist in determining the age of foals.

Declarations: Approval was given by the University of Central Lancashire Animal Projects Committee. There were no sources of funding and no competing Interests.

\title{
Keywords:
}

Horse; foal; hoof growth.

\section{Introduction:}

Thoroughbred foals stand within minutes of birth on hooves developed in utero which are covered by eponchinium, also known as deciduous hoof. This is shed within a few days in a healthy foal (Bragulla,2003). From birth a growth ring is present in the hoof parallel to the coronary band (Figure 1). The horn proximal and distal to this line often differ in colour (Ellis,1998) (Figure 2). Smallwood et al (1986) noted that in lateromedial radiographs of young foals an indent in the hoof wall, desribed in this paper as a 'foal hoof crease' (FHC) was seen on all four hooves, marking the event of foaling. Butler and Hintz (1977) studied the rate of hoof growth of 14 Shetland pony foals of eight to eleven months of age and did not mention the FHC. The hoof growth ring has been used in other species to calculate age of the new born (Brinkman (2004). 
The term 'foal foot' has been used to describe the hoof distal to the FHC (Ellis, 1998). This is a misnomer as the the hoof distal to the FHC grows in utero and should therefore more correctly be termed 'fetal hoof'. The hoof proximal to the FHC, which grows post partum, should be termed the 'foal hoof'.

Hoof wall renewal in all ages of horses has been poorly reported. Kainer (1987) stated that the time for the hoof at the toe to grow to the distal border as 270 to 365 days. Hoof growth rates in mature horses have been reported without stating hoof wall renewal time (Faramarzi et al, 2009; Reilly et al, 1998). In a case of total hoof wall avulsion of a four year old Quarter Horse, it was reported that 24 months after the trauma the hoof had completely regrown implying that this was the length of time for hoof renewal in this case (de Gresti et al, 2008). A number of authors have speculated that the hoof wall grows faster in young horses but only two have measured hoof growth rates in foals (Smallwood et al, 1986; Butler and Hintz, 1977). Neither studies investigated the time required from birth to replace the hoofcapsule or wall.

Foals often suffer partial hoof wall avusion which may cause lameness and threaten sales value. When there are lesions to the hoof wall it is useful to have an estimation of hoof capsule renewal time. The objective was to measure the time taken for the fetal hoof of newborn foals to grow to the bearing border and be replaced by hoof grown since birth.

\section{Method:}

Foals from four stud farms $(\mathrm{N}=150)$ were assessed prior to and after routine hoof trimming at three week intervals. Each foal was noted as to whether the fetal hoof was visible prior to hoof trimming. All hooves were trimmed by the same experienced farrier. Following foot trimming the presence or absence of $\mathrm{FHC}$ was determined in both front hooves. Where the fetal hoof was no longer visible post trim, the date was noted with the date of birth. The data were tabulated in Excel, analysed in Minitab and assessed for normality (Anderson- Darling). Only data from foals with no history of lameness, illness or stable confinement were analysed.

\section{Results:}

The number of foals in this study which fulfilled the criterion where the fetal hoof was present prior to routine trimming and was removed was 45 . The mean age at which the fetal hoof was trimmed out was $145 \pm 15$ days (95\% confidence interval, 141.77147.16), range $120-165$ days (Figure 3 ).

\section{Discussion:}

This study suggests that Thoroughbred foals renew their fetal hoof wall at approximately 145 days This was half the time estimated by previous authors for mature horses. This is not surprising as the foot of a foal is smaller and therefore there is less distance for the hoof to grow from the site of origin at the coronary band to the bearing surface. Additionally it has been reported that the foal hoof grows faster than mature horses (Butler and Hintz, 1977).

The cause of the $\mathrm{FHC}$ is not known but may be a consequence of the foal changing from in utero non-weight-bearing to weightbearing following birth. Another factor that may cause the FHC is the diet change of the foal associated with switching from nutients passed via the placenta to milk supplied by the mare and other feed such as grass taken orally. Cows have rings on their horns marking one for each calfing 
(Blowey, 2005). This would suggest that prominent rings in horn production in animals may be produced by changing factors other than weight-bearing. In mature horses prominent growth rings have been associated with lameness and sudden changes in dorsal wall angulation (Dyson et al, 2011).

Partial hoof wall avulsions are a frequent occurrence, although total hoof avulsion has been rarely reported (Parks, 2008). Once the initial lesion has been treated and epithilialisation has begun it is useful to be able to predict the time that it will take for the new hoof generated from the coronary band to grow down to the distal border. Sub-mural abscessation often erupts at the coronary band causing a horizontal crack in the hoof wall. The hoof wall will usually break when this nears the distal border and again it is useful to predict when this may occur in order to take preventative measures. Knowing the time that hoof renewal takes allows farriers, horse owners and veterinary surgeons to make an accurate prediction. Further studies in older horses are needed to make similarly accurate predictions.

The limitations of this study resided in the methodology. As the trimming schedule was every 21 days this may mean that the accuracy of the data was \pm 21 days. Further study is required to find the hoof growth rate of Thoroughbred foals.

\section{Materials:}

1. Excel 2007 (version 12), Microsoft Corp., One Microsoft Way, Redmond, WA98052-6399, USA.

2. Minitab 16, Minitab Inc. Quality Plaza, 1829 Pine Hall Rd., State College, PA 16801-3008, USA.

\section{References:}

Bragulla H. "Fetal Development of the segment-specific papillary body in the equine hoof." Journal of Morphology 258 (2003): 207-224.

Brinkman TJ, Monteith KL, Jenks JA, Deperno CS. "Predicting the neonatal age of White-Tailed deer in the northern Great Plains." The Prairie Naturalist, 2004: 75-81.

Butler KD, Hintz HF. "Effect of level of feed intake and gelatin supplementationon growth and quality of hoofs of ponies." Journal of Animal Science, 1977: 257-261.

de Gresti A, Zani DD, D'Arpe, Scandella M. "A singular case of traumatic hoof capsule avulsion." Equine Veterinary Education, 2008: 406-410.

Dyson SJ, Tranquille CA, Collins SN, Parkin TDH, Murray RC. "External characteristics of the lateral aspect of the hoof differ between." The Veterinary Journal, 2011: 364-371.

Ellis, DR. "Conditions of the hoof wall in young horses and corrective farriery with regard to limb deformities." Equine Veterinary Journal, 1998: 42-47.

Faramarzi B, Thomason J J, Sears W C,. "Changes in growth of the hoof wall and hoof morphology in response to regular periods of trotting exercise in

Standardbreds." American Journal of Veterinary Research 70 (2009): 1354-1364. 
Kainer RA. "Functional anatomy of equine locomotor organs." In Adams' lameness in horses, by Stashak T, 5. Philadelphia: Lea \& Febiger, 1987.

Reilly JD, Cottrell DF, Martin RJ, Cuddeford DJ. "Effect of supplementary dietry biotin on hoof growth and hoof growth rate in ponies: a controlled trial." Equine Veterinary Journal, Suppliment 26, 1998: 51-57.

Smallwood JE, Albright SM, Metcalf MR, Thrall DE, Harrington BD. "A xeroradiographic study of the developing equine foredigit and metacarpophalangeal region from birth to six months of age." Veterinary Radiology 30, no. 3 (1989): 98110.

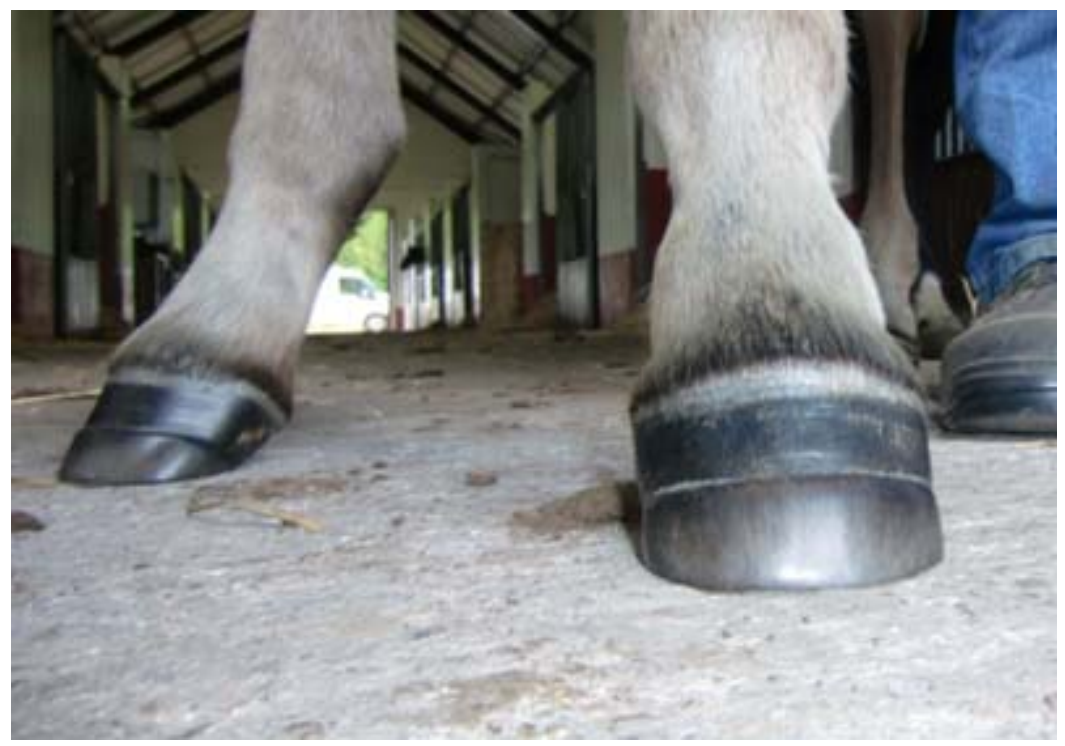

Figure 1: A foal of approximately two months age showing the foal hoof crease on both front hooves, marking the time of birth.

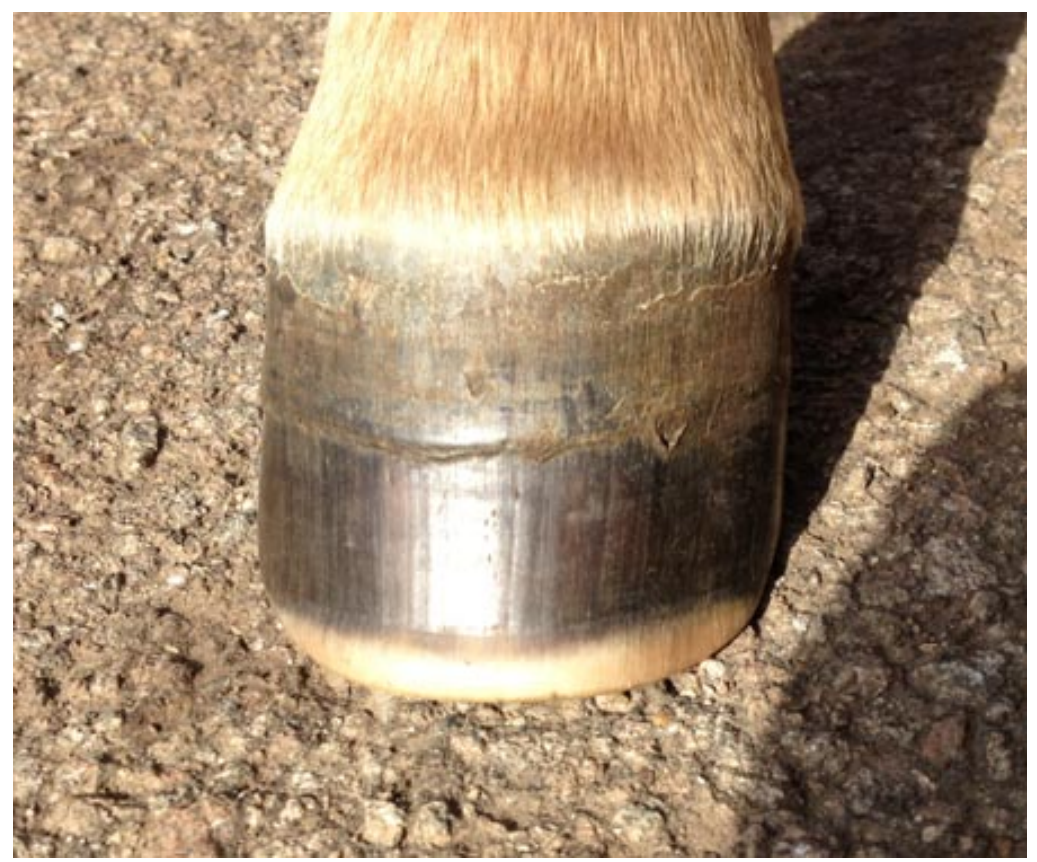

Figure 2: A foal of approximately 4 months of age with dark foal hoof proximal to the FHC and distal light coloured fetal hoof. 


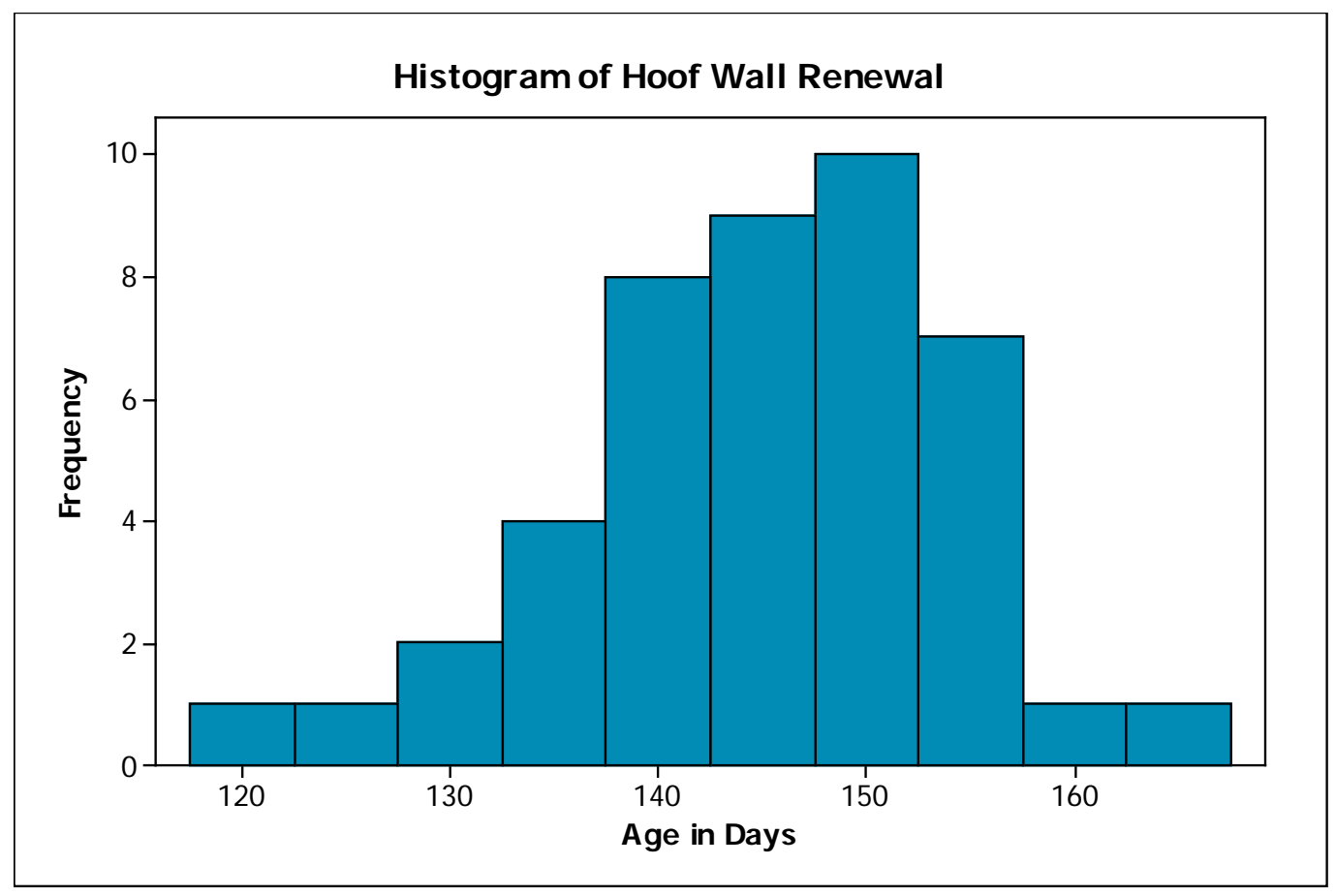

Figure 3: Histogram of the age at which the FHC was trimmed out. 